\title{
Sweet Spots for Hot Spots? A Cost-Effectiveness Comparison of Two Patrol Strategies
}

\author{
Christopher Gibson $^{1} \cdot$ Molly Slothower ${ }^{2}$. \\ Lawrence W. Sherman ${ }^{2}$
}

Published online: 6 November 2017

(C) The Author(s) 2017. This article is an open access publication

\begin{abstract}
Research Question Can police substantially reduce targeted patrol time without increasing crime and disorder in crime hot spots already receiving high levels of patrol, at high-risk times, to find a more cost-effective 'sweet spot' level of patrol staffing for each hot spot?

Data Merseyside Police measured police presence every 5 min via GPS location trackers from body-worn police radios for five pairs of matched geo-fenced hot spots of crime and disorder in a larger night-time economy area. Crime and incident data were also collected in each of the ten hot spots, over two nights on each of six consecutive weekends, with matched crime data from the same 12 nights 1 year earlier, and matching GPS data from two weekend nights before the 6-week experiment.

Methods The research design was a Maryland-Scale Level 4 test in which a group of five pairs of hot spots was randomly divided into one member of each pair receiving substantially reduced patrol time compared to the standard level received by the other member of the pair. The five experimental hot spots received at least 12-15 min of police presence every hour. Higher levels of patrol were maintained or increased in the control group consisting of the other five hot spots. Patrol time in the 'reduced patrol' experimental group was tracked and supervised closely with weekly individual feedback to a uniformed team of one sergeant and three constables. Another 40 uniformed officers working the larger area (including the five control group hot spots) were tracked to ensure they stayed out of the experimental hot spots.

Findings The experiment delivered $35 \%$ less police time in treatment hot spots than in patrol hot spots. Total incidents reported by citizens to police dropped for the five 'reduced-patrol' experimental hot spots but not for the five high-patrol control spots.
\end{abstract}

Molly Slothower

mps71@cam.ac.uk

1 Merseyside Police, Liverpool, UK

2 Universities of Cambridge and Maryland, Cambridge, MD, USA 
The cost of policing the experimental group was estimated at $£ 2380$, compared to $£ 3977$ for the control group, for financial cost savings of $40 \%$.

Conclusions The promising findings from this small-scale pilot study provide a good case for replications, using longer time periods or more hot spots for greater statistical power. If a range of patrol times per hour can be compared within matched pairs of hot spots, police commanders and patrol teams may be able to find an optimal 'sweet spot' of crime prevention without excess patrol for each kind of hot spot. This approach appears to offer great potential for redirecting police time to prevent even more harm in other places or with other kinds of police work.

Keywords Hot spots · Patrol sweet spots · GPS tracking · Night-time economy areas · Cambridge Crime Harm Index (CCHI) · Deterrence theory

\section{Introduction: Sweet Spots for Hot Spot Patrol Levels}

The fact that increases in uniformed police patrols can reduce crime and disorder in micro-place hot spots, relative to low levels of random patrol, has been well established by numerous experiments in the USA (Sherman and Weisburd 1995; Ratcliffe et al. 2011; Braga et al. 2012; Telep et al. 2014) and the UK (Ariel et al. 2016). What remains unknown, however, is whether reductions can be made in patrol time relative to high levels of patrol presence in hot spots without causing measurable increases in crime or disorder. The failure of most reported hot spots experiments to report any measure of patrol time in hot spots (Braga et al. 2012) makes the answer to this question of reduced patrol time elusive. Yet if research can find a 'sweet spot' (Cambridge Dictionary 2017) at which patrol levels are not too low but not too high, there is great potential to use police crime prevention strategies more effectively.

The concept of a 'sweet spot' comes from sports in which balls are hit, denoting 'the part of a surface that is the best or most effective possible place to hit something:

The new tennis rackets are lighter, stronger, and have a bigger sweet spot.' (Cambridge Dictionary 2017). The relevance of this concept to hot spots patrol is clear: having too much police presence in some locations may not only waste money but also threaten police legitimacy. The identification of 'sweet spots', however, may vary widely across different kinds of hot spots; busy train stations, for example, may have a different sweet spot of optimal patrol presence than a large shopping mall. It seems unlikely that police could find a uniform pattern across all hot spots similar to the physics of the sweet spot of a single racquet hitting all kinds of tennis balls. But what research could help to find is a 'sweet spot' for patrol dosage in each hot spot. This process might be accomplished by short-term experimentation with each hot spot, using the kind of methods reported in this article.

Our research addressed one widely identified candidate for seeking sweet spots of extra police presence at high crime times. That candidate is the category of places and times known in the UK as 'Night-Time Economy (NTE) Areas', also known in the USA as entertainment districts. These areas are known for predictably high levels of violence and disorder. While cities like Washington DC once under-policed such areas (Sherman 1990), contemporary English policing strategy now invests heavily in these areas. Yet the increased patrols are not always targeted at the specific micro-places 
where crime itself is most concentrated (Weisburd 2015). Instead, they may be allocated in undirected patrols across a wider area containing many such hot spots. At the same time, both the hot spots and the wider area may be receiving too much police presence, or at least more than is necessary to prevent most of the crime that would have occurred without extra police presence.

At a time in which police budgets in the UK have been declining for almost a decade, the question of whether any policing target gets too much investment is a timely policy issue. It is also an opportunity to understand more about the basic science of deterrent effects in policing. In both ways of thinking about the question, there is a major opportunity to reduce police time in hot spots patrol that could be better spent preventing even greater harm, such as gang violence, domestic abuse and cyber-fraud.

\section{The Liverpool Experiment: Operation Reddleman}

The City of Liverpool, served by the Merseyside Police, has a major NTE area in its centre, receiving massive police presence on Friday and Saturday evenings year-round. Like most such areas, crime is heavily concentrated within this area in hot spots. Unlike most such areas, the Liverpool NTE offers a GPS tracking system for measuring police presence precisely in different locations. These data show that in some hot spots, police patrols are present up to $100 \%$ of the high-crime times from 1900 to $0700 \mathrm{~h}$ on both Friday and Saturday. This contrasts sharply with the 1-year average of police presence for $15 \%$ of high-crime times (based on observers using stopwatches) that reduced crimes in 50 experimental hot spots in Minneapolis (Sherman and Weisburd 1995) compared to 50 control group hot spots that received only $7 \%$ of time with police presence. Even lower dosage of police presence was documented in the Sacramento (Mitchell 2017) and Birmingham city-centre (Williams and Coupe 2017) experiments. Thus, the far higher baseline levels of patrols in Liverpool than in previous experiments provide an ideal opportunity for careful testing of ways in which police resources might be re-directed to gang violence (see Carr et al. 2017) or other crimes with higher aggregate levels of harm (Sherman et al. 2016) - in order to reduce the overall level of crime harm in the community.

The sweet spot to be identified in Liverpool, or at least approximated, is the level of police presence beyond which extra resources add minimal benefit in crime prevention. While reducing police services is the focus of national conversation over police budget cuts in Britain since 2010, there is very little evidence to answer a key question: can a targeted hot spots patrol pattern accomplish the same outcomes (at least at the hot spots) with fewer officers (at substantially less cost) than a general area patrol pattern? The purpose of this article is to address that key question of cost-effectiveness.

Like the majority of Metropolitan policing area city centres, Liverpool has a large and diverse night-time economy business community with an average footfall of 180,000 revellers per weekend. The city centre night-time economy accounts for approximately a quarter of all Liverpool Basic Command Unit stranger violent crime incidents. Due to the large volume of alcohol-related crime and disorder incidents at peak weekend periods, additional staff from wider policing teams are deployed to the city in order to provide extra visibility and resilience. On average, in early 2016, every Friday and Saturday evening between the hours of 2100 and 0700, Merseyside Police deployed approximately 40 uniformed staff for proactive preventive patrols, over and 
above the resources required for routine 'response' policing. Much of the extra staffing comes from a force-wide Tactical Policing Team whose primary aim, Sunday to Thursday, is to proactively and overtly disrupt organised criminal groups who are often linked to firearm discharges within highly populated residential areas. In order to provide resources for the weekend NTE patrols, all available Tactical Team officers are redeployed away from gang violence-unless a specific community threat intervenes. If the number of officers for that redeployment could be reduced, without adverse effects on public safety, then the Tactical Policing Team could pursue its primary role of targeting organised crime groups in outlying communities during weekend peak periods.

Building on the extensive experimental evidence on hot spots policing, the first author developed a pilot test named 'Operation Reddleman', a reference to the agricultural occupation of marking certain lambs with red paint (as a reddleman does). The definition of the operation was to provide adequate coverage to a group of five major NTE hot spots on weekend nights with just four uniformed officers, with no patrol presence by any other officers. The purpose of the operation was to answer several operational questions about delivering the definition, and one big research question about its effects on crime and disorder.

\section{Research Question}

The first operational question was whether it was feasible to track police dosage in geofenced hot spots in the Liverpool city centre in real time, given the technical challenges faced in other police agencies (Goddard 2013; Sherman et al. 2014). If it was, the harder question was whether police patrol time could be tightly controlled in hot spots, after implementation challenges in other experiments (Sherman and Weisburd 1995; Williams and Coupe 2017). Third, in order to reduce patrol time, the next question was whether tracking could be used to keeping other police out of the area, limiting patrols there to the assigned team in order to keep the treatment hot spots 'sterile'. If all three operational questions could be answered with a 'yes', then Operation Reddleman could answer the big research question: Can high levels of patrol time be reduced from very high levels in night-time hot spots to lower levels without discernible effects of increased crime and disorder?

\section{Data}

The Liverpool City Centre neighbourhood beat (designated E9) averages 30 calls for police service per night during each combined Friday-Saturday peak time period. As of April 2016, there were 913 licenced premises in E9 including public houses, restaurants, night clubs, takeaways, hotels and cafes - an increase of 75 from 2015. Two of E9's highest-incident hot spots were Concert Square and Temple Court, both surrounded by numerous licenced premises, taxi-ranks and fast food outlets. Concert Square attracted a high footfall of people at peak times and was a focal point for alcohol-related incidents of disorder and serious assault. The location has been recognised as a significant high-crime 'place'. 
In 2016, Merseyside Police identified crime and disorder hot spots via daily monitoring of volume crime and calls for service data. Force analytical staff reviewed these data daily on a local and force level to report on 'clustering' of offences/incidents in concentrated locations referred to as 'hot spots'. There was currently no standard force definition of a 'hot spot', so places given that name varied greatly in size and numbers of incidents and crimes - sometimes across large areas without clear boundaries. That practice made it difficult to deploy resources to specific locations. The standard weekend operation loosely adopted a hot spot approach as officers are generally deployed out on foot patrol as a high visibility presence at the hot spots during peak hours.

Definition of Night-Time Economy (NTE) Crime Prior to conducting Operation Reddleman, a definition of a night-time economy crime/incident was produced to ensure that the nature of alcohol-related crime and disorder was properly reflected in the data collection process. This definition included the following: Violence against the Person (common assault to homicide), Public Order, Rape \& other Sexual Offences, Drugs Possession \& Use, Theft From Person, Theft Other and Anti-Social Behaviour. Domestic Violence incidents were removed if they were residential or in hotels. Those in public places remained in the dataset; this classification was performed manually by the police analysts.

Analysis of Crime/Incidents Once this definition had been agreed upon, temporal analysis was conducted of all the crimes/incidents reported in the city centre (under the offence categories listed above) for the calendar year 1 January 2015 to 31 December 2015 (see table one below) using the force's recording systems, Niche (Merseyside crime recording system) and Storm (Merseyside incident management system). The peak NTE crime hours were between 00:00 and 03:59, so Operation Reddleman focused on those hours on Friday evening into Saturday morning and Saturday evening into Sunday morning.

The next stage of analysis involved loading the crimes/incidents on to XD mapping to gain an understanding of where the 'hottest' areas in terms of volume of crime were. A Kernel Density Estimation analysis was run which plotted the data on to a map in clusters, showing the concentrations of crime in colour (red being the most dense in terms of volume of data). This map showed three distinct hot spots (see Fig. 3 below) Concert Square, Fleet Street/Slater Street junction and Seel Street. In order to generate more hot spots for analysis, the search parameters (grid size/search radius) were reduced and this in turn highlighted ten hot spots in total.

Eligibility Criteria of a Hot Spot Adapting the eligibility criteria of a hot spot as defined by Goddard (2013), the following parameters were established and applied to the data set: a hot spot is

- not greater than $25,500 \mathrm{~m}^{2}$ (allowing visual contact with all of the boundaries)

- a place with at least 20 crimes within the hot spot between 00:00 and 04:00 h, Friday-Sunday morning, over a 12-month period

- geographically separated from other hot spots to allow a minimum of $15 \mathrm{~m}$ buffer zones around each hot spot (test for any displacement or diffusion of benefits from treatment hot spots) 
The purpose of the buffer zones is to test for any displacement of crime or incidents into the immediate surrounding areas, or (to the contrary) any 'diffusion of benefits' of reduction in crime and disorder in areas surrounding treatment hot spots.

Exclusion Process Based on the eligibility criteria above, the ten hot spots that had been identified were then further scrutinised with a 'cleaning' process that involved case-by-case reviews of crime incident reports to check their specific location of occurrence. Some incident locations had been incorrectly inputted into the force systems, and it was imperative to ensure that the data was as accurate as possible to guarantee that the correct hot spots were identified.

\section{Design and Methods}

The ten hot spots were then plotted onto a map with the 15-m buffer zones, but a number of them overlapped. To resolve that issue, they were reshaped into polygons around the hot spot areas, following the buildings and road. This reduced the size of the hot spots and in turn reduced the amount of overlap in buffer zones.

Once the ten hot spots had been identified, they were then paired together by crime volume data so they could be separated into treatment and control groups. Due to large variances in levels of NTE crime and disorder across the hot spots, it was decided that this method of pairing would help to reduce the differences between the treatment and control groups and in doing so increases the internal validity of the trial (Weisburd 2005). Table 1 shows the hot spot pairings based on the number of night-time economy crimes for the calendar year 2015 .

Treatment and Control Groups Following the pairing of the hot spots, they were then randomly separated into treatment and control groups. The five randomly selected treatment hot spots received a highly controlled patrol dosage of 12 to $15 \mathrm{~min}$ per hour in each of the $4 \mathrm{~h}$ of Operation Reddleman per night. One patrol crew consisting of four officers (one Sergeant and three Constables) in an unmarked police vehicle visited each of the four treatment hot spots. An unmarked police vehicle was used by the officers patrolling the treatment hot spots to reduce the presence of the officers contaminating other hot spots, due to the close proximity of some. The Treatment officers were instructed to get out at each hot spot and patrol the hot spot as normal, engaging with the public and dealing with any incidents as they occur.

By running the experimental operation from 00:00 to 04:00 h each night, each of the five treatment hot spots had 48 to 60 min total dosage over the $4 \mathrm{~h}$. Anticipating that this theoretical time would be reduced by such practical matters as travelling between hot spots, comfort breaks for the officers and unforeseen circumstances, the trial's planners agreed that a 'compliance time' would allow a minimum of $10 \mathrm{~min}$ in each hour. Each treatment hot spot would then have a target of a total of 40 min dosage time across each 4-h period, a total of 480 min dosage for the entire trial of 12 nights.

The five randomly chosen control group hot spots were assigned to receive the standard model of NTE policing which did not identify where the hot spots were. Because the hot spots analysis in this trial was done for the first time only for the trial, with no prior marking of hot spots for the $\sim 40$ extra officers on preventive patrol, the 
Table 1 Hot spot pairings based on night-time economy crime for calendar year 2015

\begin{tabular}{|c|c|c|c|}
\hline $\begin{array}{l}\text { Hot spot } \\
\text { pair numbers }\end{array}$ & $\begin{array}{l}2015 \text { Night-time } \\
\text { economy crime }\end{array}$ & $\begin{array}{l}\text { Polygon } \\
\text { measurements }\left(\mathrm{m}^{2}\right)\end{array}$ & $\begin{array}{l}\text { Treatment }(\mathrm{T}) \\
\text { or control }(\mathrm{C})\end{array}$ \\
\hline \multicolumn{4}{|l|}{ Pair 1} \\
\hline Concert Square & 169 & 4150 & $\mathrm{~T}$ \\
\hline Temple Court & 109 & 5362 & $\mathrm{C}$ \\
\hline \multicolumn{4}{|l|}{ Pair 2} \\
\hline Wood Street & 82 & 2343 & $\mathrm{~T}$ \\
\hline Fleet Street/Slater Street & 105 & 2496 & $\mathrm{C}$ \\
\hline \multicolumn{4}{|l|}{ Pair 3} \\
\hline Seel Street & 75 & 2472 & $\mathrm{~T}$ \\
\hline Victoria Street/North John Street & 47 & 3190 & $\mathrm{C}$ \\
\hline \multicolumn{4}{|l|}{ Pair 4} \\
\hline Slater Street & 37 & 2192 & $\mathrm{~T}$ \\
\hline Back Berry Street & 29 & 1978 & $\mathrm{C}$ \\
\hline \multicolumn{4}{|l|}{ Pair 5} \\
\hline Bold Street Hanover & 24 & 2564 & $\mathrm{~T}$ \\
\hline Duke Street & 26 & 2858 & $\mathrm{C}$ \\
\hline
\end{tabular}

control group hot spots were not assigned any particular level of patrol. Rather, they received the level of patrol that occurred intuitively to the constables and patrol officers in the area. The only thing the control group officers were told was where the treatment hot spots were, so that they could be instructed to stay out of them or they would be identified as having 'breached' the geo-fenced boundaries of the treatment hot spots. Like the special team of four assigned to police the treatment spots, the control group officers were also instructed to provide a combination of high-visibility foot patrol and static patrol on the streets, indoor visits to licenced premises and parking in police vehicles with uniformed officers inside.

The locations of the control hot spots were not disclosed to any of the officers involved in the operation, so that no one would inadvertently change the way they policed the control areas (Fig. 1).

The general instructions not to enter into the treatment group boundaries did not include any calls for service that were made from the hot spots; officers were advised they were able to enter into hot spots to deal with such incidents. Patrols were also permitted to travel through the hot spots if needed to whilst attending any incidents, but they were instructed to avoid this by taking alternative routes if possible.

Other units (Dog section, Armed response, Mounted patrols etc.) were also advised of the trial with the same instructions.

\section{Temple Court and Concert Square Pairing}

As Table 1 shows, the two hot spots that experienced the greatest volume of night-time economy-related crimes during 2015 were Temple Court (109 NTE crimes) and Concert Square (169 NTE crimes). Both areas had a large concentration of licenced 


\section{Control Hot spots}

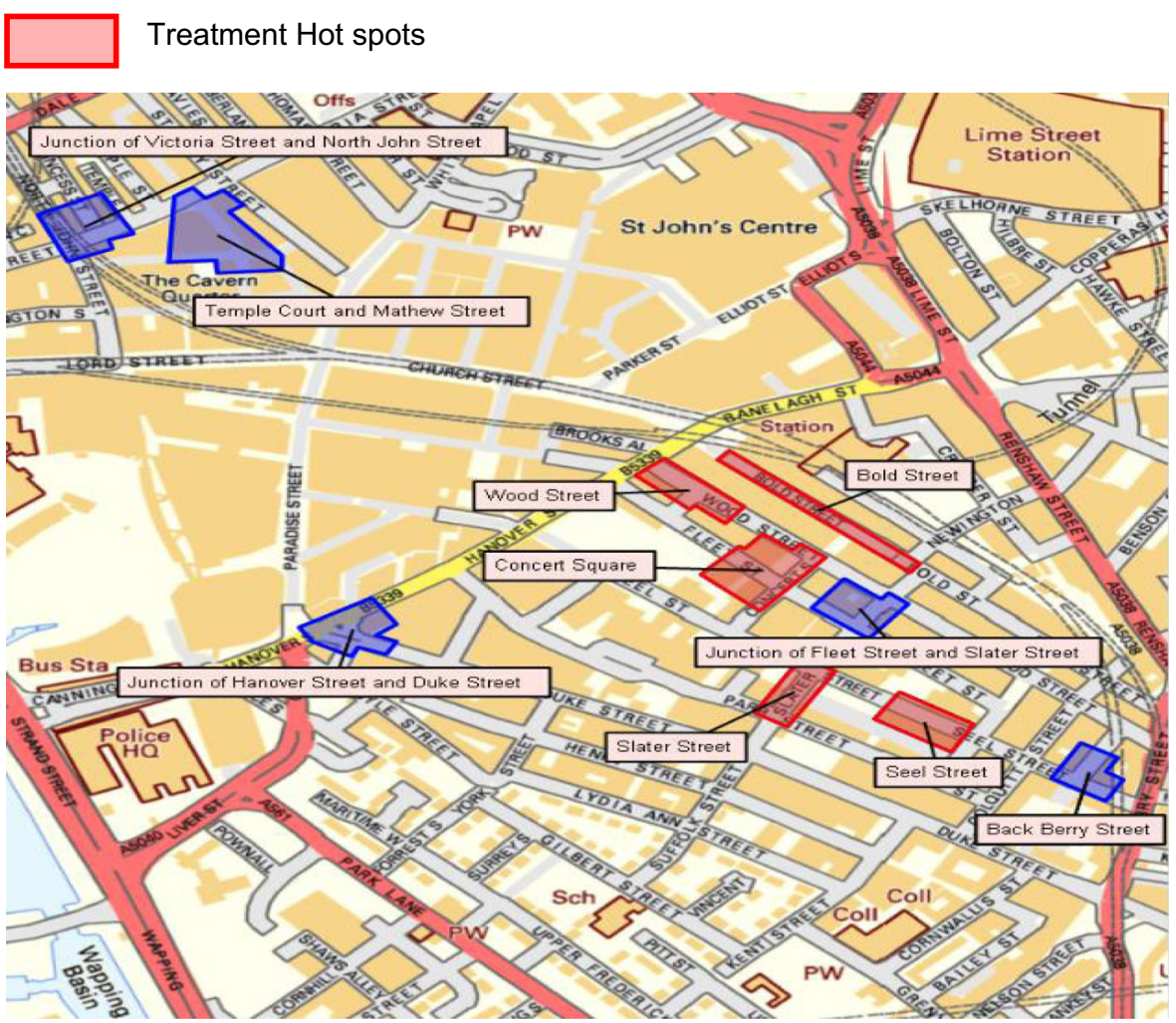

Fig. 1 Map of Liverpool city centre showing control/treatment hot spots

premises within their boundaries; they were extremely popular with younger city-centre revellers. Historically, both Temple Court and Concert Square have experienced high volumes of night-time economy crime over a number of years. As a result of this, the policing response has been to ensure a static, continuous, highly visible foot officer presence during the hours of approximately 23:00 and 05:00.

In 2016, it was the policing norm that during these hours, both of these top-ranked hot spots were to be policed by approximately 12 officers at any one time. Thus, for the one assigned to Treatment (Concert Square), the reduction to four officers patrolling around $17 \%$ of the time constituted a planned reduction of $66 \%$ in the number of officers, plus $83 \%$ in the amount of time they were there-or from 4320 officer-minutes per night to 40 , a reduction of over $90 \%$. This was a substantial change for this one pair of hot spots, which could be considered to be a stand-alone experiment in itself.

\section{Monitoring the Hot Spot Patrol Dosage}

In order to measure the dosage levels at the treatment hot spots, the officers involved in the trial were each given a specially modified Airwaves radio for the operation. These radios had been altered to send a GPS signal every $1 \mathrm{~min}$, compared to the regular 
5 min of the control group officers' normal radios. This allowed the treatment group officers to be tracked real time on a map using the same software program (XC Mapping) used to identify the hot spots. The geo-fenced polygons for each hot spot were loaded onto this system so the control room operators could see when an officer was in the polygon. The operators closely monitored the polygons via the live-time GPS tracking system to ensure that the treatment hot spots were not contaminated with any avoidable police presence outside of the (maximum) 15-min dosage periods.

Because the control group radios sent signals every 5 min while the treatment group sent them at 1-min intervals, it was necessary to get an equivalent measure in order to compare the two. To allow this comparison, the 1-min data from XC Mapping was aggregated into 5-min intervals throughout the 4-h period of each night. This created 48 equal intervals for each night of the operation. Analysis was then carried out for each of the Control and Treatment hot spots for each night of the operation. This measure provided a reliable tracking of the proportion of either officer presence or no officer presence (officer presence being one or more officers' radios having transmitted a signal), as in Fig. 2.

Figure 2 demonstrates that nine of the 5-min intervals had one or more officers present in the Wood Street hot spot, representing 19\% coverage.

A live Tactical Control Room was utilised during the hours of the operation where a Chief Inspector would be in overall command of the operation. The Chief Inspector also had access to live GPS mapping systems in order to track officers' movements in and around the hot spot areas via their personal 'Airwave' radio handset, the accuracy of which had been satisfactorily tested prior to the trial. Further contingencies relating to CCTV coverage of the hot spots and Body Worn Video footage were also utilised.

Officer 'Buy-In' Face-to-face briefings were conducted by the first author in order to clarify officers' responsibilities the importance of their role in the delivery of the experiment. During the trial, a weekly 'feeding back' performance meeting was also chaired by the first author. The aim of this meeting was to address any operational issues in the short term and to hold individuals to account on their specific responsibilities.

Ethical Considerations As the trial left the treatment hot spots without any visible police presence outside of the 10-15 min dosage target, it was acknowledged that this could have implications for public safety if incidents of crime and disorder began to increase. Since the control (status quo ante) strategy already generated many periods of intermittent if any patrolling in some locations, this dimension of the trial was not seen as a substantial risk. Other precautions against undue harm and risk included substantial CCTV coverage of the experimental hot spots, which were closely monitored from the Tactical Control Room. Furthermore, the hot spots are all relatively close in proximity

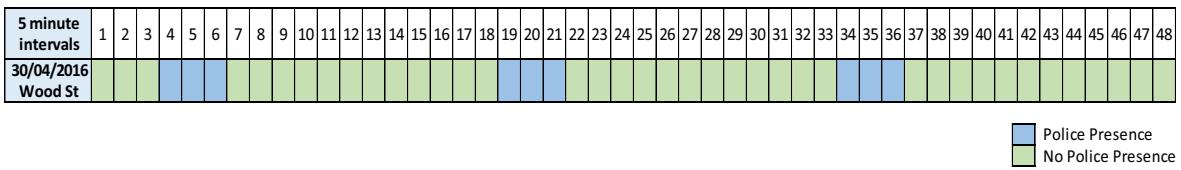

Fig. 2 Example of officer coverage in Wood St on 30/04/16 00:00 to 03:59 
so if a call for service was made from one of the treatment hot spots, officers on the regular operation were never a great distance away.

\section{Findings}

The overall finding of the test was that the treatment hot spots received substantial reductions in patrol dosage with no apparent increase in crime and an overall reduction of incidents. One illustration of this pattern is Fig. 3, in which the upper (blue) lines show the before-during comparison between one measure of patrol dosage (one weekend night just before the experiment began versus the 12 nights of Operation Reddleman). In the lower (red) lines, the number of incidents in the same areas on the same weekends in 2015 is compared to the actual count of incidents on those nights during Operation Reddleman in 2016.

Many other findings in this analysis are reported in Gibson (2016). The present report focuses on the key findings.

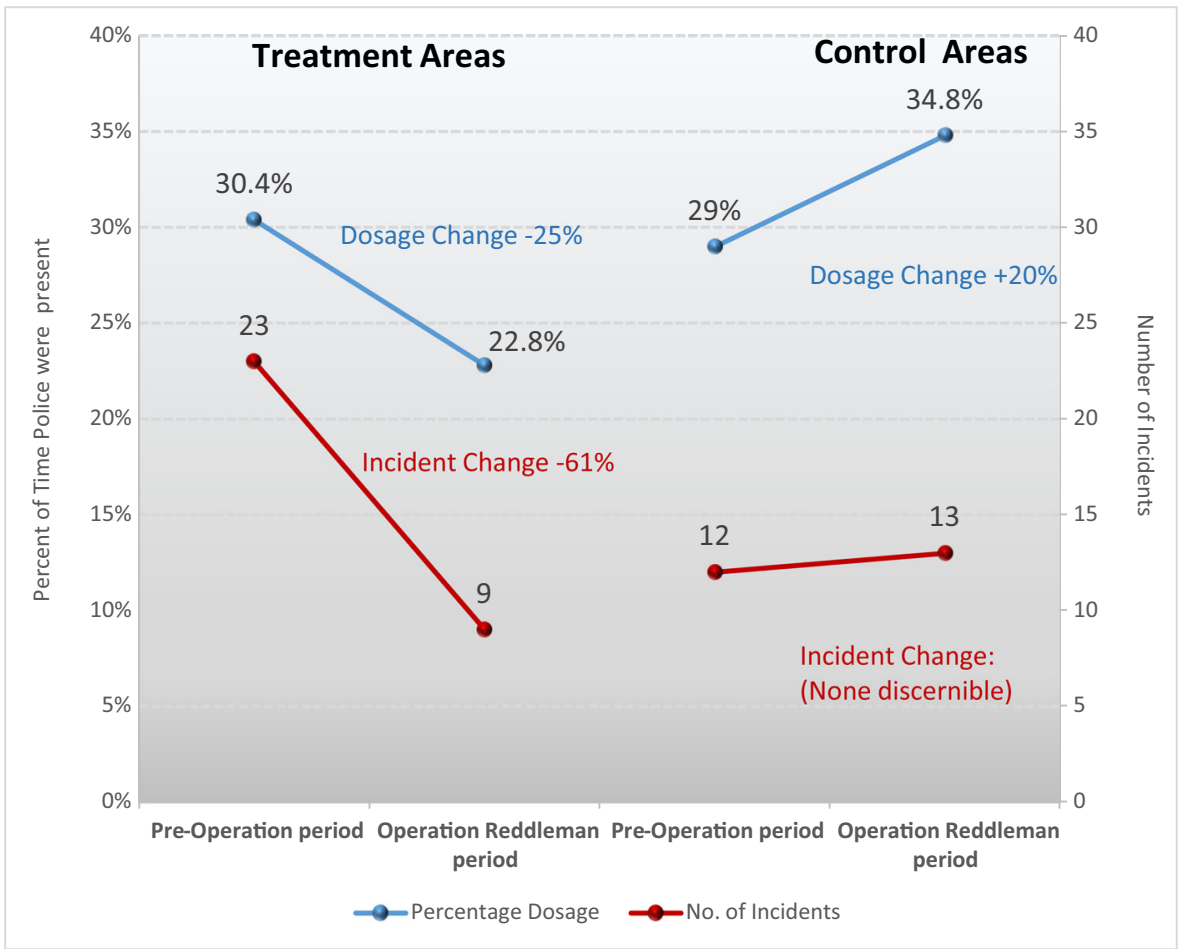

Fig. 3 Patrol dosage and citizen-reported incidents, five Treatment versus five Control group hot spots; dosage measured one weekend before; incidents measured same dates 1 year prior and experimental Operation Reddleman period 


\section{Patrol Dosage}

The first finding of this test was that it delivered and recorded substantially lower levels of patrol dosage in the treatment group hot spots than in the patrols. The second finding is that the test substantially reduced the range of different dosage levels of patrol presence in the five treatment spots (from 7 to $90 \%$ before, a spread of $83 \%$ time, to 17 to 31 , a spread of $14 \%$ time) but not in the controls (from a spread of 80 to a spread of 84). This is evident in Table 2.

\section{Daily Dosage in Treatment Areas}

Another key operational finding is that the experimental team of one sergeant and three officers implemented a highly consistent delivery of similar dosage levels of patrol across the 12 nights of the experiment in each of the five treatment hot spots during the hours of 00:00 and 03:59. Figure 4 displays the officer coverage for those assigned to policing the treatment areas (i.e. those with the trial radios with the adjusted frequency) and differs little from the data including all police presence (Gibson 2016, figs. 19 and 20).

The 40 min expected dosage per day (see above) represents eight 5-min intervals. This represents $17 \%$ of the 48 intervals within the 4 -h period. This is represented by a dashed compliance line on the chart. The solid upper limit line represents the maximum dosage a hot spot could have received if the officers rotated around the hot spots without any unforeseen circumstances or officer breaches. This would only be likely to happen in one hot spot area per night but this would have been minimal.

Table 2 Average percent of time with any patrol officer coverage for ten hot spots before and during Operation Reddleman

\begin{tabular}{llll}
\hline & $\begin{array}{l}\text { Baseline weekend } \\
02-03 / 04 / 16\end{array}$ & $\begin{array}{l}\text { Operation Reddleman } \\
12 \text {-night average }\end{array}$ & $\begin{array}{l}\text { Percent } \\
\text { change }\end{array}$ \\
\hline $\begin{array}{l}\text { Control group hot spots } \\
\text { Hanover St and Duke St Jct. }\end{array}$ & $5 \%$ & & $+200 \%$ \\
Temple Court & $85 \%$ & $15 \%$ & $+2 \%$ \\
Victoria St and North John St Jct. & $11 \%$ & $86 \%$ & $+200 \%$ \\
Back Berry Street & $8 \%$ & $31 \%$ & $-75 \%$ \\
Fleet St and Slater St Jct. & $36 \%$ & $2 \%$ & $+11 \%$ \\
Treatment group hot spots & & $40 \%$ & \\
Bold Street & $24 \%$ & & $0 \%$ \\
Concert Square & $90 \%$ & $24 \%$ & $-66 \%$ \\
Seel Street & $17 \%$ & $31 \%$ & $0 \%$ \\
Slater Street & $7 \%$ & $17 \%$ & $+200.3 \%$ \\
Wood Street & $14 \%$ & $23 \%$ & $+36 \%$ \\
\hline
\end{tabular}




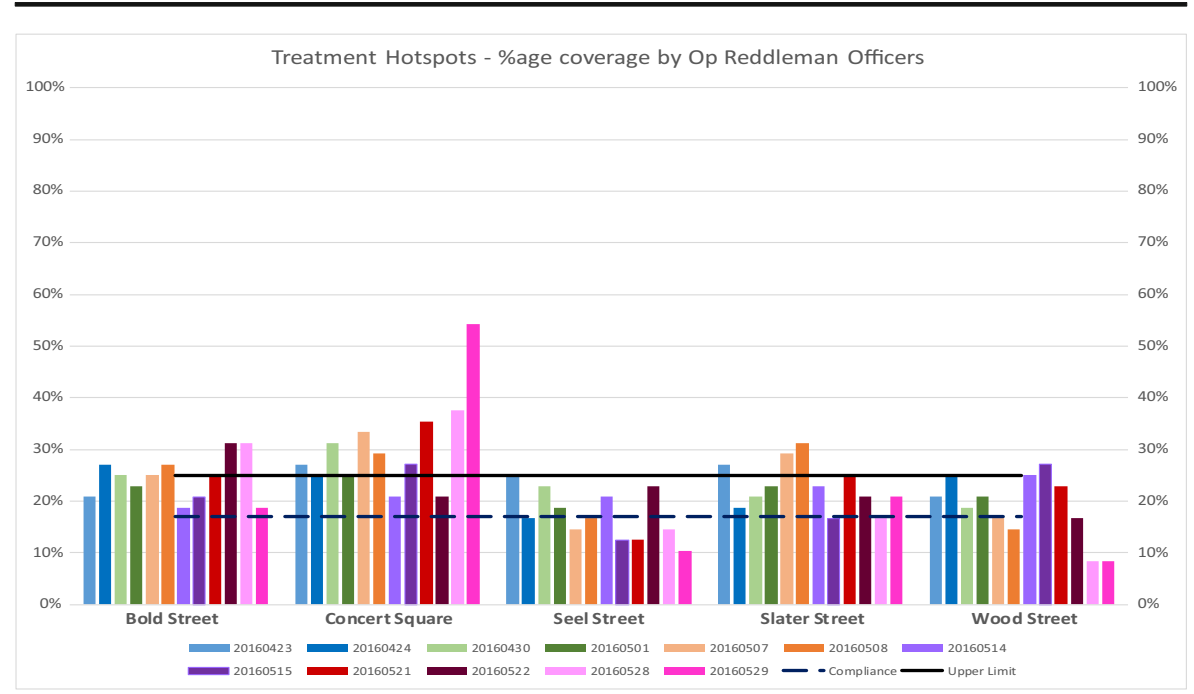

Fig. 4 Daily patrol dosage in treatment areas (Reddleman Officers only)

\section{Citizen-Reported Incidents}

This section focuses on incident data as an indicator of disorder in the ten hot spots. The methodological issue was whether altering police patrol dosage had any effect on the method for reporting crimes and if this could explain any measured difference between the treatment and control groups. As a check, incident data were divided into two categories of origin: (1) citizen call to police and (2) officer at scene (including officer witness and reported to an officer). The reason for re-classifying the data into two distinct categories is to determine whether the lack of police presence caused a change in reporting patterns. Would the treatment cause both an increase in calls to the police and a reduction in reporting to officers at the scene, or only one or the other? The evidence showed almost identical proportions of incidents based on calls to police (two thirds) in the year prior and experimental year periods (Gibson 2016).

Results in Relation to the Comparison Between the Crimes Occurring in the Matched Hot Spot Pairs During Operation Reddleman Test

As described in the methodology, the 2015 crime data showed high variances of crime volumes between the ten hot spots.

Comparison Between the Crimes and Incidents Occurring in the Hot Spots During the Test Period and the Same Period in 2015

Whilst the differing treatments were only applied during the 2016 period, it is useful to compare whether there were any differences between the two periods. The table below shows the number of incidents, 'All crimes' and 'NTE crimes' for each of the hot spots and a comparison with the same period last year. The comparative period used commenced 25/04/15-31/05/15 between the hours of 00:00 and 04:00 Saturday and Sunday mornings (Table 3 ). 
Table 3 Volumes of crime and incidents during Op. Reddleman compared to the same period in 2015

\begin{tabular}{|c|c|c|c|c|c|c|c|c|c|}
\hline & Incidents & $\begin{array}{l}\text { Incidents } \\
\text { last year }\end{array}$ & Variance & $\begin{array}{l}\text { All } \\
\text { crime }\end{array}$ & $\begin{array}{l}\text { All crime } \\
\text { last year }\end{array}$ & Variance & $\begin{array}{l}\text { NTE } \\
\text { crime }\end{array}$ & $\begin{array}{l}\mathrm{N} \text { T E } \\
\text { crime last } \\
\text { year }\end{array}$ & Variance \\
\hline Concert Square & 2 & 6 & -4 & 20 & 25 & -5 & 19 & 24 & -5 \\
\hline Bold Street & 2 & 1 & 1 & 4 & 1 & 3 & 4 & 1 & 3 \\
\hline Seel Street & 1 & 4 & -3 & 7 & 7 & 0 & 7 & 7 & 0 \\
\hline Slater Street & 1 & 2 & -1 & 5 & 7 & -2 & 5 & 7 & -2 \\
\hline Wood Street & 3 & 10 & -7 & 5 & 6 & -1 & 5 & 6 & -1 \\
\hline Treatment areas & 9 & 23 & -14 & 41 & 46 & -5 & 40 & 45 & -5 \\
\hline Temple Court & 6 & 5 & 1 & 12 & 17 & -5 & 10 & 16 & -6 \\
\hline $\begin{array}{l}\text { Victoria } \\
\text { Street/North } \\
\text { John Street }\end{array}$ & 1 & 0 & 1 & 0 & 3 & -3 & 0 & 3 & -3 \\
\hline $\begin{array}{l}\text { Hanover } \\
\text { Street/Duke } \\
\text { Street }\end{array}$ & 2 & 4 & -2 & 1 & 2 & -1 & 1 & 2 & -1 \\
\hline $\begin{array}{c}\text { Back Berry } \\
\text { Street }\end{array}$ & 0 & 0 & 0 & 2 & 1 & 1 & 2 & 1 & 1 \\
\hline $\begin{array}{l}\text { Fleet } \\
\text { Street/Slater } \\
\text { Street }\end{array}$ & 4 & 3 & 1 & 7 & 10 & -3 & 7 & 10 & -3 \\
\hline Control areas & 13 & 12 & 1 & 22 & 33 & -11 & 40 & 32 & -12 \\
\hline
\end{tabular}

In the five treatment hotspots, 41 crimes were committed over the 6-week period of Operation Reddleman. In comparison to a similar period last year, there were 46 crimes committed. This is a reduction of five crimes representing an $11 \%$ decrease during the experimental period. Concert Square, where patrol was reduced the most, saw the largest decrease (five crimes) and Bold Street was the only one of the five treatment hotspots to see an increase (just three more crimes). There is insufficient statistical power in these tests to draw conclusions about differences of such small magnitude. Yet it seems clear that the major changes in patrol dosage levels caused no substantial increase in disorder or crime in the treatment group.

Examining the types of crime that were recorded, violence has shown a reduction in the hot spot areas receiving treatment. In 2015, there were 28 violence offences of all kinds in the five treatment hot spots; during the operational period this count dropped to six violence offences of all kinds, a $79 \%$ decrease.

In relation to calls for service, there was also a reduction of 14 incidents, most evident in Wood Street and Concert Square. ASB incidents did not feature during the analysis.

The control areas that received 'routine policing' also saw a reduction in crimes over the 6-week period of Operation Reddleman. During the operation, there were 22 crimes committed, compared to 33 crimes in the similar period last year. This is a reduction of 11 crimes representing a 33\% decrease. These increases were mainly evident in Temple Court and the junction of North John St/Victoria Street. Again, this reduction in crime has been in violence offences. There were 13 crimes last year compared to four for the 
operational period this year. In contrast, there was no reduction in calls for service for the hot spots that received the standard model of non-hot spot policing.

These decreases in crimes could suggest that the hot spots within E9 neighbourhood have moved since the original analysis of 2015 data. Analysis was conducted to determine if this was the case. 'NTE crimes' for the period January-April 2016 were examined. Temporal analysis replicated the findings of the initial analysis of the 2015 crimes, confirming that the peak times of 00:00 to 04:00 was still apparent. These 'NTE crimes' were then loaded into XD mapping I.T. system. A Kernel Density Estimation map demonstrated the same hot spots for January-April 2016 as for January-April 2015 (Gibson 2016).

\section{Displacement or Diffusion of Crime Control Benefits}

In order to test for displacement of crime to immediately adjacent to the ten hot spots, a 15-m buffer area surrounding each hot spot was examined for both the period of Operation Reddleman and the same period in 2015 (Gibson 2016, figs. 11 and 12). During the period of Operation Reddleman, there were 15 crimes that occurred in the buffer zones around the ten hot spot areas. Eleven of these crimes occurred in the buffers surrounding the treatment hot spots. In comparison with the same period in 2015, there were only five crimes within the same treatment buffer zones. While the numbers are small, there would appear to be some possibility of displacement of crimes into the surrounding areas of the treatment areas. When examining the offences undertaken, 7 of the 11 crimes in the treatment hot spots buffer zones were for theft.

\section{Cambridge Crime Harm Index}

The volumes of crimes committed within each of the hot spot areas have been multiplied by the CHI values from the University of Cambridge (Sherman et al. 2016). An overall score has been calculated for the Control and Treatment areas for the 6-week period of Operation Reddleman and a similar 6-week period in 2015. The overall score has also been calculated excluding proactively generated crimes such as possession of drugs (see Gibson 2016, fig. 25).

Comparing the Operation Reddleman period to the same period the year before, the Cambridge CHI score dropped in the Treatment hot spots from 233 in 2015 to 116.5 in 2016. The CHI score for the control areas dropped from 188 in 2015 to 111.5 in 2016. These two trends are very similar and clearly show no higher CHI scores in the treatment group despite its reduction in total cost of police resources.

An even clearer test of the CHI differences is found in a specific comparison of the two highest-crime hot spots, Concert Square in the Treatment group and Temple Court in the Control group. As previously discussed, both Concert Square and Temple Court are high crime areas and (in 2015) both generally received a static, continuous highly visible officer presence during the targeted weekend hours. This was the only pairing that tested a full 'flooded' patrol strategy in the Control group and the much-reduced patrol strategy in the Treatment group. During the Operation Reddleman period, both areas experienced a decrease in their CHI score. However, the reduction in the treatment group (Concert Square) had proportionately greater improvement in $\mathrm{CHI}$ 
outcomes, dropping by $75 \%$ (from $\mathrm{CHI}=113.5$ in 2015 to $\mathrm{CHI}=27.5$ in 2016) compared to a drop of only 54\% in the control area (from CHI = 147 in 2015 to $\mathrm{CHI}=67$ in 2016).

\section{Direct Cost Comparison}

By analysing individual officer's GPS Airwave radio signals, it is possible to evidence an approximate direct cost of both policing tactics during the hours of the experiment. The direct cost excludes the indirect costs of hiring, training, supervising, equipping and maintaining a police service; direct costs focus solely on salaries of the front-line officers involved. It is worth noting that the following analysis is approximate and is reliant upon the registered 'pings' of the individual GPS signals. The methodology for calculating the costs of Treatment group versus Control group policing is as follows:

Average constable hourly rate $=£ 17.44$ (current as of 2016).

Average constable minute rate $=£ 0.29$.

Average constable $5 \mathrm{~min}$ rate $=£ 1.45$.

Within the $4 \mathrm{~h}$ of the operation, there were 48 intervals of 5 min each. From the GPS signal readings from the radios registered in each hot spot, the first author counted the number of unique radios within each 5-min interval. He then added these up for the 12 nights and then multiplied the volumes by the $5 \mathrm{~min}$ rate.

The approximate cost of policing the Treatment group hot spots during Operation Reddleman was $40 \%$ lower than in the Control group hot spots. The estimated cost of standard policing in the Control group during the Reddleman period (based on 5-min GPS readings) was $£ 3977.77$. The same cost for the treatment group hot spots was $£ 2380.56$.

When the same comparison is made just for the two highest-crime hot spots, the proportionate cost of the treatment group was $76 \%$ lower in the Treatment group's Concert Square than the cost of the continuous static patrol in the Control group's Temple Court hot spot. As shown above, both hot spots received officer presence during the weekend hours of operation for approximately $90 \%$ of their annual deployments. This tactic continued in the Temple Court (control) area during the Operation Reddleman period (at 86\%). In stark contrast, during the Reddleman period, Concert Square received approximately 15 min worth of policing by the four dedicated dosage officers resulting in an officer presence of $31 \%$ during the $96 \mathrm{~h}$ of the experiment. Effectively, this area remained 'police free' for $45 \mathrm{~min}$ of every hour of the Reddleman period. The cost for the Treatment group policing in Concert Square was only $£ 652$ compared to $£ 2694$ for the Control group strategy in Temple Court.

\section{Conclusion}

The results presented above show that Operation Reddleman was successfully delivered as designed. Based on precise GPS measures of each individual officer, the standardised patrol dosage was delivered as planned in the Treatment group. Although the dosage in the control groups turned out to be somewhat different from expectations, the fact that it increased simply showed how uncontrolled the non-hot spot strategy is by its very nature. 
These results allow us to answer the research question in the affirmative, within the limits of the study design. The costs of previously high levels of patrol dosage in a major 'night-time economy' entertainment area can be reduced by switching from a 'flooded' random patrol strategy to a targeted hot spots patrol without evidence of any adverse impacts on crime. The 'sweet spot' of less expensive patrol for essentially the same outcomes would seem to include the dosage level of 15 min of each hour, unpredictably and randomly rotated from one hot spot to another by a fourofficer team.

Because the findings showed no change or a reduction in the volume of reported crime and disorder, this could enable Merseyside police to reduce the number of police officers deployed to night-time economy operations and to redirect scarce resource to competing policing demands for crime harm reduction.

This short 6-week test is admittedly low in statistical power, and replications of the test would be advisable in the course of any policy changes based on these results. The primary point is that it now seems safe to conduct such short tests in any matched pair of hot spots in order to reduce costs to find a 'sweet spot' for those hot spots.

This conclusion is especially clear when the analysis is limited to the two largest and most expensively policed hot spots in the experiment. Both the Concert Square Treatment hot spot (where costs were reduced 76\%) and the Temple Square Control group hot spot saw a reduction in the seriousness of offences committed within them (based on the Crime Harm Index analysis). If the same downward trend can be obtained at much lower costs, there seems every reason to attempt this now in both locations and in similar locations served by other police agencies.

The findings of this experiment also provide evidence of strong implementation that further studies can learn from and build upon. To our knowledge, this is the first study of hot spots policing of any kind that has delivered this level of operational control and precision of its dosage in treatment groups. It was apparent early on in the planning stage that successful delivery would depend upon a robust tracking plan and officer buy in (Fixsen et al. 2005). A police Tactical Commander at Chief Inspector rank was identified and appointed providing strong leadership and ownership of the operational delivery of the experiment. Over the six weekends of the trial, this officer delivered two operational briefings per night to over 450 operational police personnel. A detailed outline of both policing tactics was provided and all staff left the briefing with maps of the treatment areas and a clear understanding of their role in successful delivery. A Tactical Command suite was established on each night of the operation within the force Joint Control Centre. The Tactical Commander was able to effectively track the officers providing the treatment group dosage via their modified Airwave GPS signal on a livetime XC Mapping I.T. system. He was also able to monitor the more numerous Control group officers via their GPS signal in the control groups. The Command suite also had extensive city-centre CCTV capability allowing the Commander to visually monitor the treatment areas to ensure that the tactic was being delivered. Each of the four officers providing the treatment group dosage also had Body Worn Video (BWV) capability. The officers were instructed to activate the BWV when entering each hot spot. This footage effectively captured each officer's time in and out of the treatment hot spots and was utilised as a contingency should GPS signals fail; however, this footage was not required for the experiment due to the strong performance of the Airwave GPS system. 
This study provides firm evidence to suggest that Merseyside and other police agencies can continue to develop evidenced-based policy for policing hot spots. The approach reported here replaces a common pattern of identifying large undefined areas called 'hot spots' without clear boundaries. This in turn makes it difficult to effectively deploy resources to specific locations. A policy change, focused on the power few locations where crimes and harm are concentrated (Sherman 2007), can prioritise small, geo-fenced areas for intensive but cost-contained patrols. That is the sweet spot for more efficiently deploying targeted but reduced resources to crime prevention initiatives.

With reduced resource, accountability becomes ever more important. Merseyside police deployment strategies document the importance of ensuring that resource is in the right place at the right time. Prior to this experiment, there was little evidence of police supervisors tracking officer movements and feeding back patrolling data to first- and second-line managers. The current XC live-time mapping system is antiquated and relies on 5 min Airwave GPS signals. During this trial, the police Force Contact Centre 'Dispatch' staff reported their reluctance to utilise the system for normal operational deployment due to historical inaccuracies of the ' 5 min GPS ping'.

This trial offers important evidence on the third ' $\mathrm{T}$ ' of the 'triple- $\mathrm{T}$ strategy' for evidence-based policing (targeting, testing and tracking). It was the first time that retrospective tracking analysis had been undertaken for the use of Merseyside resource deployment, officer location and 'dosage'. Yet the current I.T. management software did not allow easy extraction of this data. It seems misguided to hold police managers to account if they do not have access to the I.T. tools to review where their officers are or have been (Sherman 2013). An effective I.T. system is needed which accurately tracks the location and patrol patterns of officers and has the capability to extract postdeployment performance tracking data with ease.

Operation Reddleman tested the effects of patrol dosage on crimes and calls for service in night-time economy hot spots by comparing treatment and control cases within five pairs, as in a Level 4 quasi-experiment (Sherman 1997; Skogan and Frydl 2003). This study lacked the randomisation and large sample size which would have given increased confidence in its internal validity. This type of design provides less confidence in demonstrating causation than a Level 5 randomised trial. Yet the strengths of this level of study include an uncomplicated design, making research more cost-effective and less disruptive to general policing than may be found with a Level 5 Randomised Control Trial (Hagan 2006).

Despite its limitations, this study addresses a major challenge facing police leaders who support evidenced-based policing. That challenge is to educate the wider workforce about the use of knowledge in policing. Finding less expensive ways to produce the same results is clearly one way to generate their enthusiasm. It is equally important that evidenced-based policing principles are driven 'bottom $/ \mathrm{mid}$ dle-up' as opposed to 'top-down' (Sherman 2013). This study engaged a large number of front-line officers in a positive, 'first-contact' experience with evidence-based policing. From the indications of further appetite for research within Merseyside Police, the experiment's most lasting effect may be to create an environment where police leaders are comfortable with adopting an experimental approach to crime prevention. 
Acknowledgements The authors acknowledge the support of Sharon Todhunter of Merseyside Police in preparing many of the data analyses. The study was made possible by a bursary from the College of Policing, matched by funding from Merseyside Police, for the first author to attend the M.St. Course in Applied Criminology and Police Management at the Cambridge Police Executive Programme, Institute of Criminology, University of Cambridge, where the master's thesis on which this article is based was supervised by the second author.

Open Access This article is distributed under the terms of the Creative Commons Attribution 4.0 International License (http://creativecommons.org/licenses/by/4.0/), which permits unrestricted use, distribution, and reproduction in any medium, provided you give appropriate credit to the original author(s) and the source, provide a link to the Creative Commons license, and indicate if changes were made.

\section{References}

Ariel, B., Weinborn, C., \& Sherman, L. W. (2016). "Soft” policing at hot spots — do police community support officers work? A randomized controlled trial. Journal of Experimental Criminology, 12(3), 277-317.

Braga, A., Papachristos, A., \& Hureau, D. (2012). The effects of hotspots policing on crime: an updated systematic review and meta-analysis. Justice Q, 31(4), 633-663.

Cambridge Dictionary (2017). "Sweet Spot”. Downloaded 29 September. http://dictionary.cambridge. org/dictionary/english/sweet-spot.

Carr, R., Slothower, M., \& Parkinson, J. (2017). Do gang injunctions reduce violent crime? four tests in Merseyside, UK. Cambridge Journal of Evidence Based Policing. Springer.

Fixsen, D. et al. (2005). (eds) 'A conceptual view of implementation' and 'conclusions and recommendations'. In Implementation research: a synthesis of the literature. Tampa: University of South Florida, pp 11-22, 67-79.

Gibson, D (2016). The effects of targeted reductions of patrol dosage on crime victimisation and costs in night time economy hotspots: a phase 1 trial. Thesis submitted for the M.St. in applied criminology and police management, Institute of Criminology, University of Cambridge.

Goddard, N. (2013). A protocol and phase 1 test for an RCT of patrol dosage in entertainment hotspots: random short visits vs. static deployment. Thesis submitted for the M.St. in applied criminology and police management, Institute of Criminology, University of Cambridge.

Hagan, F. E. (2006). Research methods in criminal justice and criminology. Boston: Allyn \& Bacon. Chapter 3. Research design: the experimental model and its variations, pp 76-114.

Mitchell, R. J. (2017). Frequency Versus Duration of Police Patrol Visits for Reducing Crime in Hot Spots: Non-Experimental Findings from the Sacramento Hot Spots Experiment. Cambridge Journal of Evidence-Based Policing, 1-16.

Ratcliffe, J. H., Taniguchi, T., Groff, E. R., \& Wood, J. D. (2011). The Philadelphia foot patrol experiment: A randomized controlled trial of police patrol effectiveness in violent crime hotspots. Criminology, 49(3), 795-831.

Sherman, L. (1990). Police crackdowns: initial and residual deterrence. Crime and Justice, 12, 1-48.

Sherman, L., \& Weisburd, D. (1995). General deterrent effects of police patrol in crime "hotspots": a randomized controlled trial. Justice Q, 12(4), 625-648.

Sherman, L. W. (2007). The power few: experimental criminology and the reduction of harm. J Exp Criminol, 3(4), 299-321.

Sherman, L. (2012). Offender desistance policing (ODP) less prison and more evidence in rehabilitating offenders. US: Hogrefe Publishing.

Sherman, L. W. (2013). The rise of evidence-based policing: targeting, testing and tracking. In M. Tonry (Ed.), Crime and justice in America, 1975-2025, crime and justice (pp. 377-452). Chicago: University of Chicago Press.

Sherman, L. W., et al. (2014). An integrated theory of hotspots patrol strategy, implementing prevention by scaling up and feeding back. Journal of Contemporary Criminal Justice, 30(2), 95-122.

Sherman, L. W., et al. (2016). Policing: a journal of policy and practice. The Cambridge crime harm index: measuring total harm from crime based on sentencing guidelines. Oxford Journal, volume, 10, 171-183.

Skogan, W., \& Frydl, K. (Eds.). (2003). Fairness and effectiveness in policing. The evidence. Washington: National Academies Press. 
Telep, C., Mitchell, R., \& Weisburd, D. (2014). How much time should the police spend at crime hotspots? Answers from a police agency directed randomized field trial in Sacramento, California. Justice Q, 31(5), 905-933.

Weisburd, D. (2005). Hotspots policing experiments and criminal justice research: lessons from the field. The Annals of the American Academy of Political Social Science, 599, 220-245.

Weisburd, D. (2015). The law of crime concentration and the criminology ofplace. Criminology, 53(2), 133157.

Williams, S., \& Coupe, T. (2017). Frequency Vs. Length of Hot Spots Patrols: a Randomised Controlled Trial. Cambridge Journal of Evidence-Based Policing, 1-17. 